\title{
Manual and rotary instrumentation techniques for root canal prepa- ration in primary molars
}

\author{
Francinne M. Rosa ${ }^{1}$, Adriana Modesto ${ }^{2}$, Italo M. Faraco-Junior ${ }^{3}$ \\ ${ }^{1}$ Private Practice, Porto Alegre, RS, Brazil \\ ${ }^{2}$ University of Pittsburgh, School of Dental Medicine, Pittsburgh, PA, USA \\ ${ }^{3}$ Private Practice, Porto Alegre, RS, Brazil
}

\section{Abstract}

Introduction: Although rotary instrumentation has been widely studied in permanent dentition, it is a rather new field of study concerning primary teeth. Purpose: We aimed to evaluate apical displacement and time needed for instrumentation of root canals of primary molars by manual and rotary techniques. Materials and Methods: Root canals of 144 extracted first and second primary maxillary molars were randomly divided into 2 groups: Imanual instrumentation (K-files); II- rotary instrumentation (K3 Rotary System®). The canals were radiographed with pathfinding files in place, prepared by both techniques, and instrumentation time was recorded. After preparation, root canals were radiographed again with pathfinding files in place. To analyze the degree of apical displacement, digital images were superimposed using the Adobe Photoshop®software. Results: Mean apical displacement $(0.70 \mathrm{~mm})$ in the manual instrumentation group was not statistically different from that in the rotary instrumentation group $(0.79 \mathrm{~mm})$. However, mean time for root canal preparation was significantly shorter using the rotary system (128.0 s) than using the manual system (174.0 s) ( $\mathrm{p}<0.05)$. Conclusions: The use of rotary instrumentation in pediatric dentistry is feasible, offering time-saving advantages in root canal preparation.
Citation: Rosa FM, Modesto A, and Faraco-Junior IM. (2014) Manual and rotary instrumentation techniques for root canal preparation in primary molars. Dentistry 3000. 1:a001 doi:10.5195/d3000.2014.19 Received: January 14, 2014

Accepted: April 24, 2014

Published: May 27, 2014

Copyright: @2013 Rosa et al. This is an open access article licensed under a Creative Commons Attribution Work 3.0 United States License.

Email: faraco@globo.com

\section{Introduction}

The use of rotary instrumentation in pediatric dentistry is a rather new field of study, although it has been widely studied in permanent dentition.

Studies have compared rotary with manual instrumentation performance for root canal preparation in permanent teeth. The results have shown no significant differences in the cleaning capacity between techniques, but rotary instrumentation prepared canals more rapidly and uniformly [1,2]. In addition, the rotary instruments can reach the entire length of the root canal, causing little or no displacement, particularly in the apical region [35].

Rotary instrumentation characteristics become significantly relevant when dealing with endodontic preparation of primary teeth, since appointment length is a crucial factor for pediatric patient compliance, and maintaining the original path of the root canal is essential to ensure the integrity of the germ of the permanent successor $[6,7]$.

Considering the reduced number of studies on this topic in pediatric dentistry, this study aimed to elucidate the apical displacement produced in root canals and the time needed for root canal preparation in primary teeth by the rotary instrumentation system in comparison with the manual instrumentation technique.

\section{Materials and Methods}

Sixty-four primary maxillary molars extracted with no previous endodontic treatment, internal and/or external root resorption, and over two-thirds of resorbed root were selected for the study. After sample size calculation (power of $90 \%$ confidence level of $95 \%$ ), the sample was composed of 144 roots (Table 1): 24 mesiobuccal, 24 distobuccal, and 24 palatal roots of the first primary maxillary molars; and 24 mesiobuccal, 24 distobuccal, and 24 palatal roots of the second maxillary molars. These roots were cleaned with periodontal curettes, decontaminated with $1 \%$ sodium hypochlorite and sterilized in $10 \%$ formalin. All teeth were previously embedded in clear acrylic-resin blocks. For this purpose, a thin layer of wax was placed on dental apex to seal the inlet channels, and the teeth were sunken until the

Table 1: Distribution of the primary molars.

\begin{tabular}{lcc|c}
\hline \multicolumn{1}{|c}{ Tooth } & $\begin{array}{c}\text { Mesiobuccal } \\
\text { root }\end{array}$ & $\begin{array}{c}\text { Distobuccal } \\
\text { root }\end{array}$ & Palatal root \\
\hline $\begin{array}{l}\text { First primary maxillary } \\
\text { molar }\end{array}$ & 24 & 24 & 24 \\
$\begin{array}{l}\text { Second primary maxil- } \\
\text { lary molar }\end{array}$ & 24 & 24 & 24 \\
\hline $\begin{array}{l}\text { Total number of each } \\
\text { root }\end{array}$ & 48 & 48 & 48 \\
\hline & Total number of roots=144 & \\
\hline
\end{tabular}

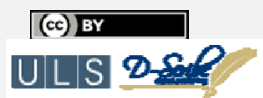

This work is licensed under a Creative CommonsAttribution 3.0 United States License.

This site is published by the University Library System, University of Pittsburgh as part of its D-Scribe Digital Publishing Program and is cosponsored by the University of Pittsburgh Press. 
Vol 2 No 1 (2014) DOl 10.5195/d3000.2014.19

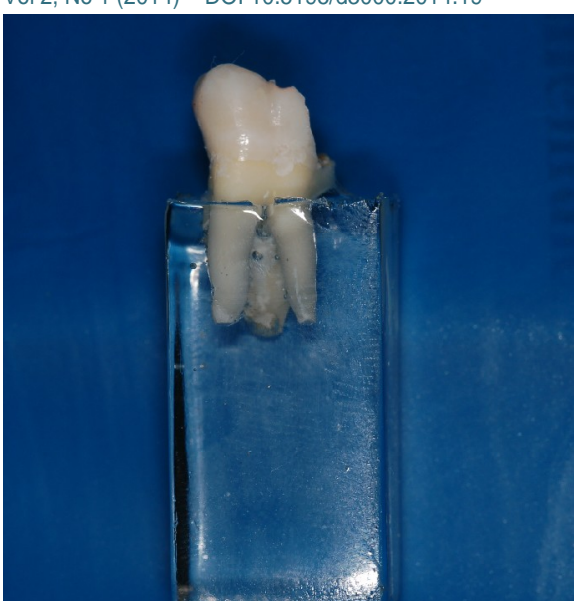

Figure 1: Tooth embedded in clear acrylic-resin block.

level of acrylic-resin covered the roots (Figure 1).

After crown access, the teeth were irrigated with $1 \%$ sodium hypochlorite and the working length was determined by passive insertion of a K-file with a rubber stop. When the file tip was at the level of the dental apex, the rubber stop was leveled with the respective cusp tip and the length of each root canal was recorded. The working length was determined by subtracting 2 (two) $\mathrm{mm}$ from the total length of the root canals.

The root canals were then placed on a radiographic platform and radiographed in proximal (mesial/distal) and frontal (palatal/buccal) directions, with pathfinding files in place, using a direct digital imaging sensor (Oygnus MPD ${ }^{\circledR}$,CygnusInc., Redwood Oty, CA, USA), in order to record pathfinding file position in the apical region of root canals. Radiographs were obtained with Gnatus X-ray equipment (Gnatus Equipamentos Médico-Odontológicos Ltda, Ribeirão Preto, São Paulo, Brazil), 70X, $70 \mathrm{kVp}$ and $7 \mathrm{~mA}$, at $30 \mathrm{~cm}$ focal distance, $90^{\circ}$ core radius, and 0.08 seconds exposure time.

Biomechanical preparation of all root canals was performed by a single operator, with resin blocks fixed on a device that secured blocks in the same position (Figure 2). Instrumentation time for each root canal was re-

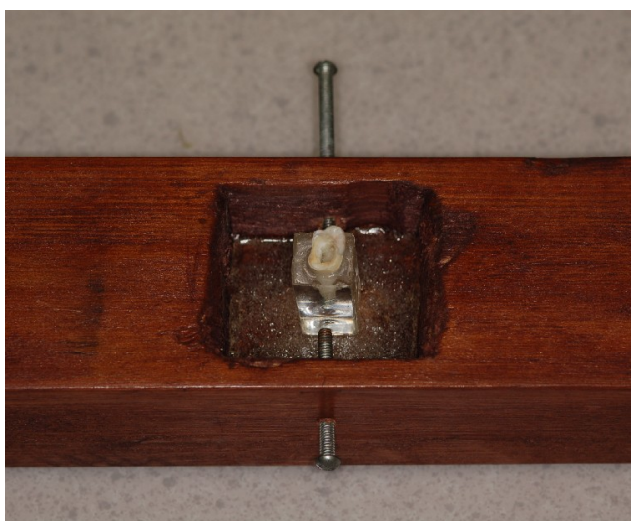

Figure 2: Acrylic-resin block positioned for instrumentation corded, and each instrument, in both groups, was used in 10 samples.

proximal view. Reproducibility of the results was verified every five images analyzed.

Table 2: Analysis of apical displacement (in millimeters) comparing the techniques used (rotary vs. manual instrumentation).

\begin{tabular}{|c|c|c|c|c|}
\hline Tooth & Root & Rotary & Manual & $\mathbf{p}^{*}$ \\
\hline 1PMM & Mesiobuccal & 0.27 & 0.43 & 0.184 \\
\hline 1PMM & Distobuccal & 0.85 & 0.63 & 0.175 \\
\hline 1PMM & Palatal & 0.24 & 0.14 & 0.839 \\
\hline 2PMM & Mesiobuccal & 0.28 & 0.56 & 0.599 \\
\hline 2PMM & Distobuccal & 0.49 & 0.35 & 0.166 \\
\hline 2PMM & Palatal & 0.38 & 0.18 & 0.049 \\
\hline
\end{tabular}

1PMM=first primary maxillary molar; 2PMM=secondary primary maxillary molar.

${ }^{*}$ Statistically significant $p$ values $(p<0.05)$. Mann-Whitney nonparametric test.

The roots were randomly divided into two groups:

- Group I ( $n=72)$ : manual instrumentation. (1) coronal opening; (2) irrigation with $1 \%$ sodium hypochlorite (performed throughout the preparation); (3) location of root canals (4) root canal instrumentation using K-files: utilization of initial instrument (better fit in the root canal) and three sequential instruments (Figure 3)

- Group II ( $n=72)$ : rotary instrumentation. (1) coronal opening; (2) irrigation with $1 \%$ sodium hypochlorite (performed throughout the preparation); (3) location of root canals (4) root canal instrumentation using with $\mathrm{K} 3 \mathrm{Ro}$ tary System ${ }^{\circledR}$ (Sybron Endo, Orange, CA, USA) in the sequences \# 25/0.8, \# 30/0.6, \# 25/0.4, and \# 25/0.2 (crown-apex direction), set in motion by an Endo Standard Pro Torque ${ }^{\circledR}$ motor (Dentsply, Ro de Janeiro, R, Brazil) at 250 rpm speed (Figure 4).

After biomechanical preparation, root canals were placed again on the radiographic platform and radiographed in proximal and frontal directions, with pathfinding files in place, being careful to maintain the same standard conditions (position and other exposure factors).

Post-biomechanical preparation radiographs were digitally superimposed over their prepreparation counterparts using the Adobe Photoshop ${ }^{\circledR}$ software (Figure 5). A straight line was drawn to connect the tips of the instruments inside the canals, thus generating two displacement measurements: one for frontal and one for proximal view. Real apical displacement was measured (in millimeters) by a pre-calibrated examiner, blinded to technique assignment, by calculating the third side of a triangle constructed by the measurement of the displacement obtained from frontal and
Student's $t$ test.

Statistical analysis was performed with the Statistical Package for the Social Sciences (SPSS) software, version 14.0, and significance level of $5 \%$ Data regarding apical displacement were compared using the Kruskal-Wallis test and the MannWhitney test. Differences in instrumentation time were statistically analyzed with ANOVA, post hoc Tukey's test, and the

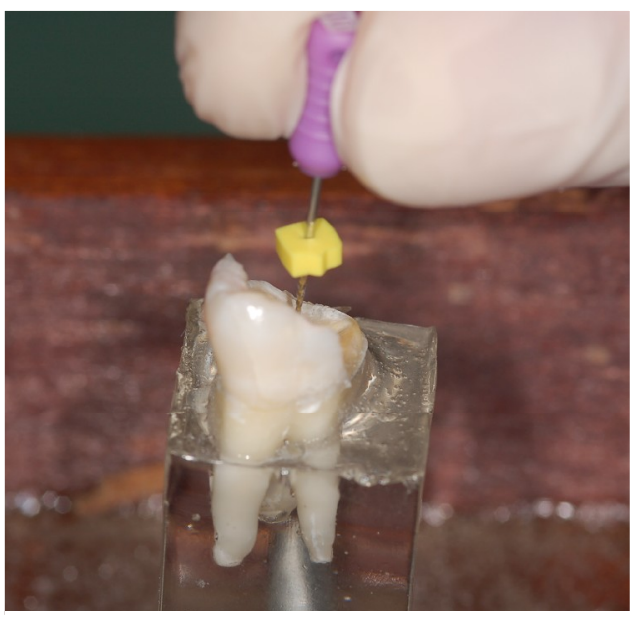

Figure 3: Manual instrumentation with K-files.

\section{Results}

In the manual group, the lowest apical displacement was observed in the distobuccal root of the first primary maxillary molar $(0.15$ $\mathrm{mm}$ ) and the greatest apical displacement was found in the mesiobuccal roots of the first and second primary maxillary molars $(1.64 \mathrm{~mm})$. In regard to the time, palatal root of the second maxillary molar showed the lowest value (121 s), and the highest value was observed in the mesiobuccal root of the second primary maxillary molar (416 s).

In the rotary group, the lowest value for apical displacement was observed in the palatal root of the first primary maxillary molar $(0.10 \mathrm{~mm})$ and the greatest value in the distobuccal root of the first primary maxillary molar $(3.09 \mathrm{~mm})$. The shortest instrumentation time in the rotary technique was observed in the palatal root of the second primary maxillary molar (78 
s) and the longest time in the mesiobuccal

tion conditions as similar as possible to in vivo conditions, since standardized root canals

Table 3: Analysis of time (in seconds) comparing the techniques used (rotary vs. manual instrumentation).

\begin{tabular}{|c|c|c|c|c|}
\hline Tooth & Root & Rotary & Manual & $\mathbf{p}^{*}$ \\
\hline 1PMM & Mesiobuccal & 163.3 & 181.8 & 0.410 \\
\hline 1PMM & Distobuccal & 149.3 & 244.6 & $0.007^{*}$ \\
\hline 1PMM & Palatal & 131.7 & 151.7 & $0.042^{*}$ \\
\hline 2PMM & Mesiobuccal & 123.7 & 256.0 & $0.001^{*}$ \\
\hline 2PMM & Distobuccal & 133.0 & 206.2 & $<0.001^{*}$ \\
\hline 2PMM & Palatal & 111.1 & 145.9 & $0.001^{*}$ \\
\hline
\end{tabular}

1PMM=first primary maxillary molar; 2PMM=secondary primary maxillary molar.

*Statistically significant $p$ values $(p<0.05)$. Student $t$ test.

root of the first primary maxillary molar (296s).

The evaluation of apical displacement for each root type, after post hoc analysis for means, comparing manual and rotary techniques, showed no statistically significant differences (Table 2).

With regard to the time needed for instrumentation using manual and rotary techniques, within the same root type group, statistically significant differences were observed in all root types, except for the mesiobuccal root of the first primary maxillary molar. The shortest time for instrumentation was achieved with the rotary instrumentation

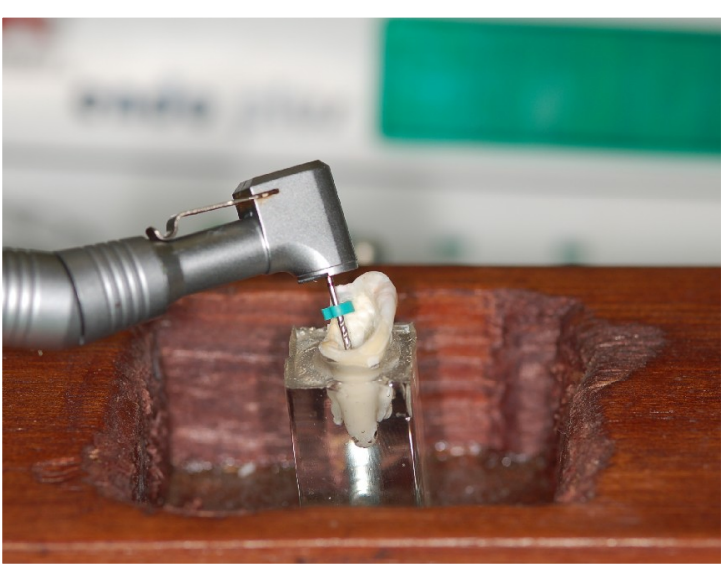

Figure 4: Rotary instrumentation with K3 Rotary System ${ }^{\circledR}$. distobuccal and palatal roots, technique (Table 3).

An overall data analysis, regardless of root type, showed no significant differences when comparing the degree of apical displacement within manual and rotary techniques. However, considering instrumentation time, the rotary technique needed a significantly shorter time than the manual technique.

\section{Discussion}

This study sample was composed of extracted primary teeth, aiming to reproduce prepara-

exclude some variables found in natural teeth [8]. Furthermore, the reduced number of studies using rotary instrumentation in primary teeth [6,7,9-19] justifies the comparison of our findings with some studies in permanent teeth [1,2,20-25].

With regard to apical displacement, there were no statistically significant differences between techniques, when root types and groups were analyzed altogether, although displacements occurred in all root types and in several ways.

used, as well as a rotary system different than the digital images.

one employed in the present study.

Furthermore, the highest values for apical displacement produced in mesiobuccal roots, which usually show a higher degree of curvature [8], occurred using the manual instrumentation technique. In however, the highest values were obtained with rotary instrumentation.

Emsallati et al. [22] showed that K3 Rotary System ${ }^{\circledR}$ produces minimum wear of root canal walls, which is an interesting aspect in the endodontic preparation of primary teeth. Moreover, Orespo et al. [11] and Musale, Mujawar [12] stated that rotary files prepared more conical canals in primary teeth than manual instruments.

When analyzing canal curvature, it is well

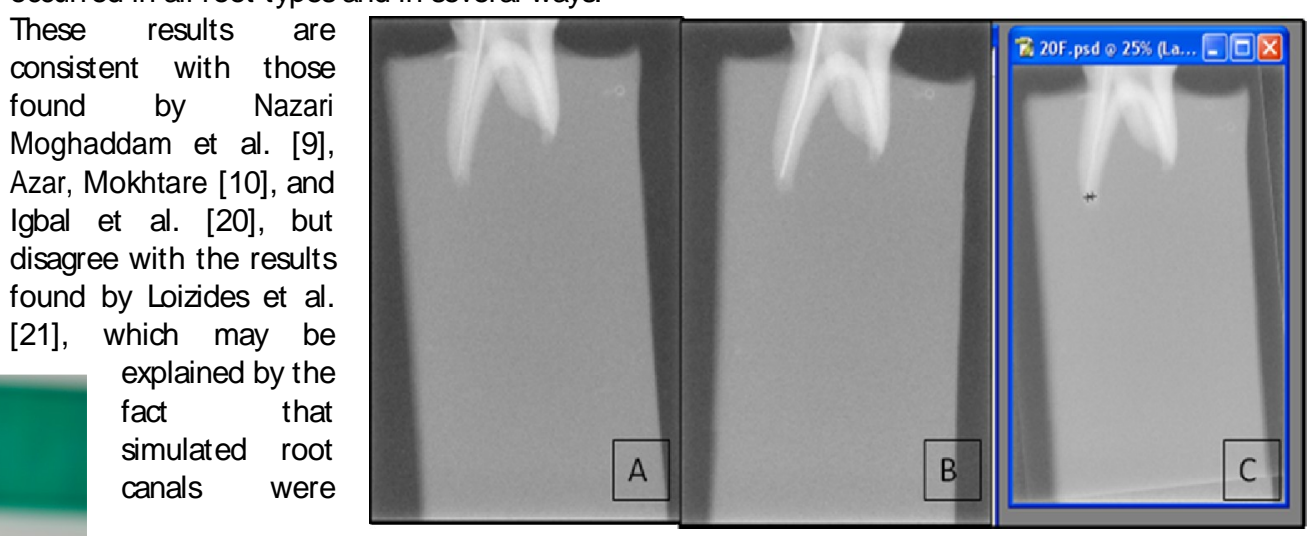

Figure 5: (A) Initial radiograph; (B) Final radiograph; (C) Overlay of known that the degree of curvature does not affect the performance of K3 Rotary System ${ }^{\circledR}$ $[23,24]$ validating the good performance of this system in mesiobuccal roots observed in this study.

In the present study, two instrument fractures were observed, both with K3 Rotary System ${ }^{\circledR}$, although this is considered one of the safest systems [23,25]. Nagaratna et al. [13], working on primary teeth, already pointed out as a disadvantage of the rotary system its higher fracture rate.

Two root perforations occurred in the present study, both in the rotary instrumentation group. Only one [14] of the previous studies performed in primary teeth [6,7,9-13,15-18] reported such event, which might be attributed to the operator's level of skill in using the system. Moreover, Kummer et al. [14] stated that in some specimens, root perforations were observed in areas coinciding with largest root resorption.

In regard to instrumentation time, when the 
tained with the manual technique, in all root types, except for the mesial root of the first primary maxillary molar. Therefore, we can state that root anatomy affects instrumentation time, since deviant root anatomy leads to longer instrumentation time for both the manual and rotary technique.

The results obtained in the present study are quite satisfactory concerning the reduction of instrumentation time by the rotary technique, a fact already reported in previous studies in primary teeth. However, there was no statistical significant difference between techniques concerning apical displacement when root types and groups were analyzed altogether, although displacements occurred in all root types and in several ways.

Pinheiro et al. [19] stated that endodontic treatment in children may be challenging and time consuming, especially during root canal preparation, which is one of the most important stages of endodontic therapy. Considering that the rotary instruments provide similar root canal cleaning compared to manual instruments with a shorter instrumentation time, their utilization is well indicated in Pediatric Dentistry.

In conclusion, rotary instrumentation is feasible and an important tool to be used in the endodontic preparation of primary teeth since it requires a shorter clinical time from the pediatric patient.

\section{Acknowledgements}

None of the authors have a direct financial relation with any commercial identities mentioned in this paper, nor have any other conflict of interests to declare. We thank Dr. Carlos Alberto Feldens for helping us in the statistical analysis.

\section{References}

1. Comparing apical preparations of root canals shaped by nickeltitanium rotary instruments and nickel-titanium hand instruments. Deplazes P, Peters O, Barbakow F.J Endod. 2001 Mar;27(3):196-202. PMID: 11487151

2. Effectiveness of manual and rotary instrumentation techniques for cleaning flattened root canals. Barbizam N, Fariniuk LF, Marchesan MA, Pecora JD, Sousa-Neto MD. J Endod. 2002 May;28(5):365-6. PMID: 12026920

3. Efficiency of rotarynickel-titaniumK3 instruments compared with stainless steel hand K-Fexofile. Part 2. Ceaning effectiveness and shaping ability in severely curved root canals of extracted teeth. Schäfer E Schlingemann R Int Endod J. 2003 Mar;36(3):208-17. PMID: 12657147

4. A comparison of Profile, Hero642, and $\mathrm{K} 3$ instrumentation systems in teeth using digital imaging analysis. González-Rodrguez MP, FerrerLuque OM. Oral Surg Oral Med Oral Pathol Oral Radiol Endod. 2004 Jan;97(1):112-5. PMID: 14716266

5. In vitro evaluation of the thermal alterations on the root surface during preparation with different $\mathrm{Ni}-\mathrm{Ti}$ rotary instruments. Capelli A, Guerisoli DM, Barbin 旦, Spanó JC, Pécora D. Braz Dent J. 2004;15(2):115-8. Epub 2005 Mar 11. PMID: 15776193

6. Use of nickel-titanium rotary files for root canal preparation in primary teeth. Barr ES, Keier DJ, Barr NV. Pediatr Dent. 1999 NovDec;21(7):453-4. PMID: 10633522

7. Use of nickel-titanium rotary files for root canal preparation in primary teeth. Barr ES, Keier DJ, Barr NV. Pediatr Dent. 2000 JanFeb;22(1):77-8. PMID: 10730297

8. A three-dimensional study of canalcurvatures in the mesial roots of mandibular molars. Ounningham CJ, Senia ES J Endod. 1992 Jun;18(6):294-300. PMID: 1402588

9. Root canal cleaning efficacy of rotary and handfiles instrumentation in primary molars. Nazari Moghaddam K, Mehran M, Farajian Zadeh H. Iran Endod J. 2009 Spring;4(2):53-7. Epub 2009 Apr 17. PMID: 23940486

10. Rotary Mtwo system versus manual K-file instruments: efficacy in preparing primary and permanent molar root canals. Azar MR, Mokhtare M. Indian J Dent Res. 2011 MarApr;22(2):363. doi: 10.4103/09709290.84283. PMID: 21891918

11. Comparison between rotary and manual instrumentation in primary teeth. Orespo S, Cortes O, Garcia C, Perez L J Gin Pediatr Dent. 2008 Summer;32(4):295-8. PMID: 18767460

12. Evaluation of the efficacy of rotary vs. hand files in root canal preparation of primary teeth in vitro using CBCT. Musale PK, Mujawar SA. Eur Arch Paediatr Dent. 2014 Apr;15(2):113-20. doi: 10.1007/s40368-013-0072-1. Epub 2013 Jul 27. PMID: 23893606
13. In vitro comparison of NiTi rotary instruments and stainless steel hand instruments in root canal preparations of primary and permanent molar. Nagaratna PJ, Shashikiran ND, Subbareddy W. J Indian Soc Pedod Prev Dent. 2006 Dec;24(4):186-91. PMID: 17183182

14. Ex vivo study of manual and rotary instrumentation techniques in human primary teeth. Kummer TR, Calvo MC, Cordeiro MM, de Sousa Vieira R, de Carvalho Rocha MJ. Oral Surg Oral Med Oral Pathol Oral Radiol Endod. 2008 Apr;105(4):e8492.

doi:10.1016/j.tripleo.2007.12.008. PMID: 18329573

15. Comparison of rotary and manual instrumentation techniques on cleaning capacity and instrumentation time in deciduous molars. Slva LA, Leonardo MR, Nelson-Flho P, Tanomaru JM. J Dent Child (Chic). 2004 Jan-Apr;71(1):45-7. PMID: 15272656

16. Comparison of conventional, rotary, and ultrasonic preparation, different final irrigation regimens, and 2 sealers in primary molar root canal therapy. Canoglu H, Tekcicek MU, Cehreli ZC. Pediatr Dent. 2006 NovDec;28(6):518-23. PMID: 17249433

17. Comparison between rotary and manual techniques on duration of instrumentation and obturation times in primary teeth. OchoaRomero T, Mendez-Gonzalez V, Flores-Reyes H, Pozos-Guillen Ad. J Cin Pediatr Dent. 2011 Summer;35(4):359-63. PMID: 22046692

18. K-file vs ProFiles in cleaning capacity and instrumentation time in primary molar root canals: an in vitro study. Madan N, Rathnam A, Shigli AL, Indushekar KR J Indian Soc Pedod Prev Dent. 2011 Jan-Mar;29(1):2-6. doi: $\quad 10.4103 / 0970-4388.79907$. PMID: 21521910

19. Evaluation of cleaning capacity and instrumentation time of manual, hybrid and rotary instrumentation techniques in primary molars. Pinheiro St, Araujo G, Bincelli I, Ounha R, Bueno C. Int Endod J. 2012 Apr;45(4):379-85.

doi: 10.1111/j.1365 2591.2011.01987.x. Epub 2011 Dec 22. PMID: 22188162

20. Comparison of apical transportation in four $\mathrm{Ni}$-Ti rotary instrumentation 
techniques. Iqbal MK, Maggiore $\mathrm{F}$, Suh B, Edwards KR, Kang J, Km S J Endod. 2003 Sep;29(9):587-91. PMID: 14503833

21. Root canal transportation with a Ni$\mathrm{Ti}$ rotary file system and stainless steel hand files in simulated root canals. Loizides A, Eliopoulos D, Kontakiotis E Quintessence Int. 2006 May;37(5):369-74. PMID: 16683684

22. Debris retention and wear in three different nickel-titanium rotary instruments. Emsallati EA, Wadachi $R$, Errahim AK, Suda H. Aust Endod J. 2006 Dec;32(3):107-11. PMID: 17201751

23. Comparative study of six rotary nickel-titanium systems and hand instrumentation for root canal preparation. Guelzow A, Stamm O, Martus P, Kelbassa AM. Int Endod J. 2005 Oct;38(10):743-52. PMID: 16164689

24. A comparative study of root canal preparation with NiTi-TEE and K3 rotary $\mathrm{Ni}-\mathrm{Ti}$ instruments. Jodway $\mathrm{B}$, Hülsmann M. Int Endod J. 2006 Jan;39(1):71-80. PMID: 16409331

25. Deformation and fracture of $\mathrm{RaCe}$ and $\mathrm{K} 3$ endodontic instruments according to the number of uses. Troian $\mathrm{CH}$, Só MV, Figueiredo $\mathrm{A}$, Oliveira $\Psi$. Int Endod J. 2006 Aug;39(8):616-25. PMID: 16872456 